\title{
Effects Of Microwave On Molten Metals With Low Melting Temperatures
}

\author{
Xiang Sun, Jiann-Yang Hwang*, Xiaodi Huang, Bowen Li, Shangzhao Shi \\ Institute of Materials Processing and Department of Materials Science and Engineering, Michigan \\ Technological University, Houghton, MI 49931
}

\begin{abstract}
:
Different metals were tested to determine if microwave irradiation can heat liquid metals. Temperature profiles of different molten metals under microwave radiation revealed that molten metals are primarily microwave reflectors. To explain this phenomenon, microwave heating mechanisms and skin depths of conductors have been introduced. The influences of resistivities on metal skin depths are also discussed.
\end{abstract}

Keywords: Microwave, Lead, Aluminum, Bismuth, Tin, Molten Metals.

\section{INTRODUCTION}

In conventional heating, heat is transferred to a material through conduction, convection and radiation. All the energy that is required to heat the material pass from the surface to the interior and the heat flow rate is constrained by temperature and thermal diffusivity.

Microwaves are electromagnetic waves with frequencies ranging between 300 $\mathrm{MHz}$ and $300 \mathrm{GHz}$. When a material absorbs microwaves, heat can be generated inside the material and heating is instantaneous with the introduction of power. Another advantage of microwave heating is that it can accelerate reaction rates and reduce reaction temperatures by decreasing activation energy [1]. An additional benefit to using microwave applications is that reactors and production facilities can be reduced to smaller volumes and sizes than needed for conventional heating, thus saving costs in capital investment, labor and energy [2]. In a major review, Sutton [3] summarized the fundamentals, benefits, challenges, and major research activities of microwave processing of materials. Because of its potential advantages, microwave heating is used for a diversity of processes in tempering, food, sterilization, drying, metal manufacturing and other industries.

Bulk metals can not be heated by microwave radiation because the incident microwaves are attenuated in a very thin surface layer, and the heating effect caused by induced currents is so small as to be irrelevant. However, for metal powders, the surface layer makes up a large proportion of the material, and the heat produced is quite significant [4]. Therefore, heating metal powders by microwave has been widely used.

\footnotetext{
* Author to whom correspondence should be addressed, Tel: 1-906-487-2600, Email: jhwang@mtu.edu
} 
Another application of microwave processing of metals is the reduction of metal oxide ores or other minerals because of the potential energy savings.

Recently microwave-assisted extraction of metals from related minerals has been developed at the Institute of Materials Processing, Michigan Technological University. Using microwaves to reduce metal oxides to their metallic forms may result in problems associated with microwave interaction with molten metals. One potential problem is thermal run away. Thermal runaway is a condition that arises when the power dissipation in a small elemental volume within a workpiece exceeds the rate of heat transmission to its surroundings, so that the rate of increase in enthalpy is greater than in the neighboring volumes. Until now, microwave absorption properties of molten metals have not been studied. Being motivated by these observations, the present study aims to investigate molten metal behavior under microwave radiation.

\section{EXPERIMENTAL PROCEDURES}

\section{Sample preparation}

Pure metallic powders of $\mathrm{Al}$ (3g), $\mathrm{Pb}$ (12.5g), Bi (10.8g), Sn (8g) were filled separately at the same volume in $99 \%$ alumina microwave transparent crucibles. The top of each crucible was covered by alumina wool to prevent heat loss. Blank samples (crucibles with no powders) were also prepared.

\section{Experimental system setup}

The experimental arrangement for measuring molten metal microwave absorption is illustrated in Figure 1. A 4.5 inch mullite pipe was placed in the middle of a microwave oven (GE, Model RVM1335, 900W, 2450MHz). Inside the oven, a heating circuit was wrapped around the pipe. Inert Argon gas entered the left side of the pipe and exited through the right side, directly into the exhaust hood. In the middle of the mullite pipe was a small plate made of pure Inconel, which has a very high melting temperature, to hold the sample and crucible. A thermocouple sheathed with Nickel-Chrome based Super OMEGACLAD ${ }^{\circledR}$ penetrated to near the bottom of the crucible, as illustrated in Figure 1. The temperature of the sample was controlled by a system connected to both the thermocouple and the heating elements. Copper tube was used to connect the gas pipe and the mullite pipe. The system, except for the temperature control system, was placed in a hood. In order to prevent any microwave effects on the thermometer, it was placed outside, at a distance of 12 inches from the cabinet.

\section{Experimental procedure}

Argon gas was passed through the mullite pipe at a flow rate of $8.5 \mathrm{~L} / \mathrm{min}$ for 15 minutes before heating, and continuously during the experiment to avoid metal oxidation. After 15 minutes of argon gas flow, the heating circuit around the mullite pipe was turned on. Heating continued until the temperature reached $300{ }^{\circ} \mathrm{C}$ above the melting 
temperature of the sample. The temperature control system was used to keep the temperature steady for 10 minutes. Under this condition, all the solids inside the crucible became liquid, as illustrated in Figure 2. Then the conventional heating circuit was turned off and the microwave oven turned on for 3 minutes. After three minutes, the microwave was turned off and the sample was allowed to cool. The temperature change was recorded throughout the heating and cooling sequence. Argon gas flow continued until the sample cooled down to room temperature to prevent reoxidation. A blank sample was also tested at each temperature.

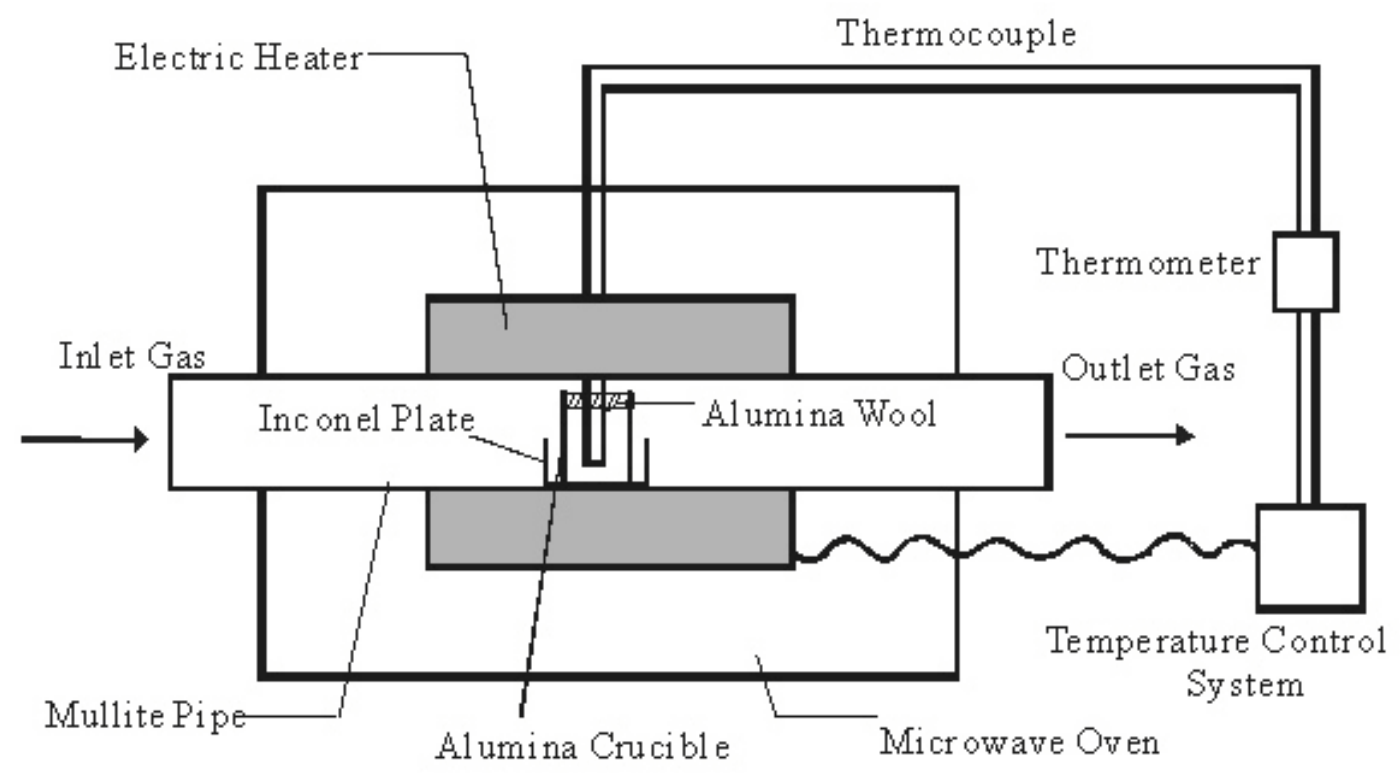

Figure 1. Schematic Diagram of the Experimental System

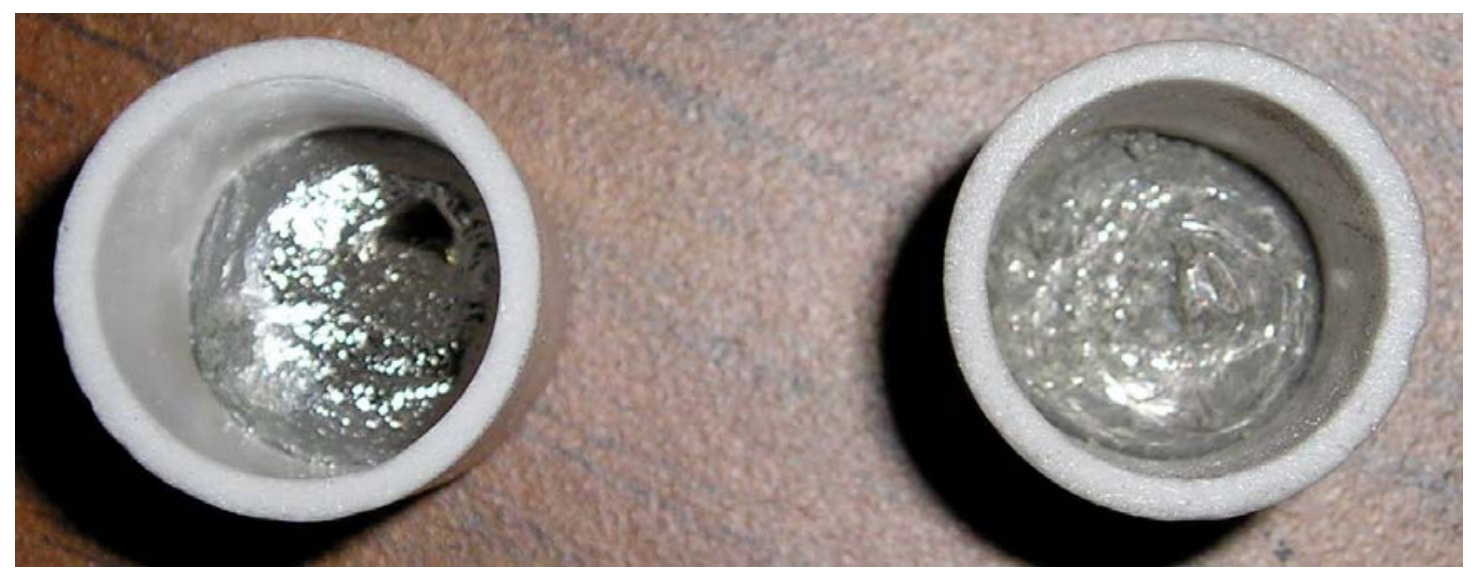

Figure 2. Molten metals $\mathrm{Pb}$ (left), Bi (right) 


\section{RESULTS AND DISCUSSION}

Figure 3 shows how the temperatures of the sample and the blanks change with time for different metals under microwave irradiation. For $\mathrm{Pb}$ and $\mathrm{Bi}$, the temperatures of the blank crucibles are slightly higher than the samples, which indicate that nearly no heat was produced inside the molten metals during the microwave period. For Al, the heat loss of the blank is slightly more than that of the sample. Sn is a little different. When subjected to microwave irradiation, the Sn sample heated up a few degrees higher than the blank. This phenomenon is not clearly understood at this time. In general, it can be clearly seen from the experimental results that molten metals are primarily microwave reflectors because there is no significant heating generated in the samples by microwave radiation. Thermal runaway was not evident, as the temperature of the samples remained constant or decreased.

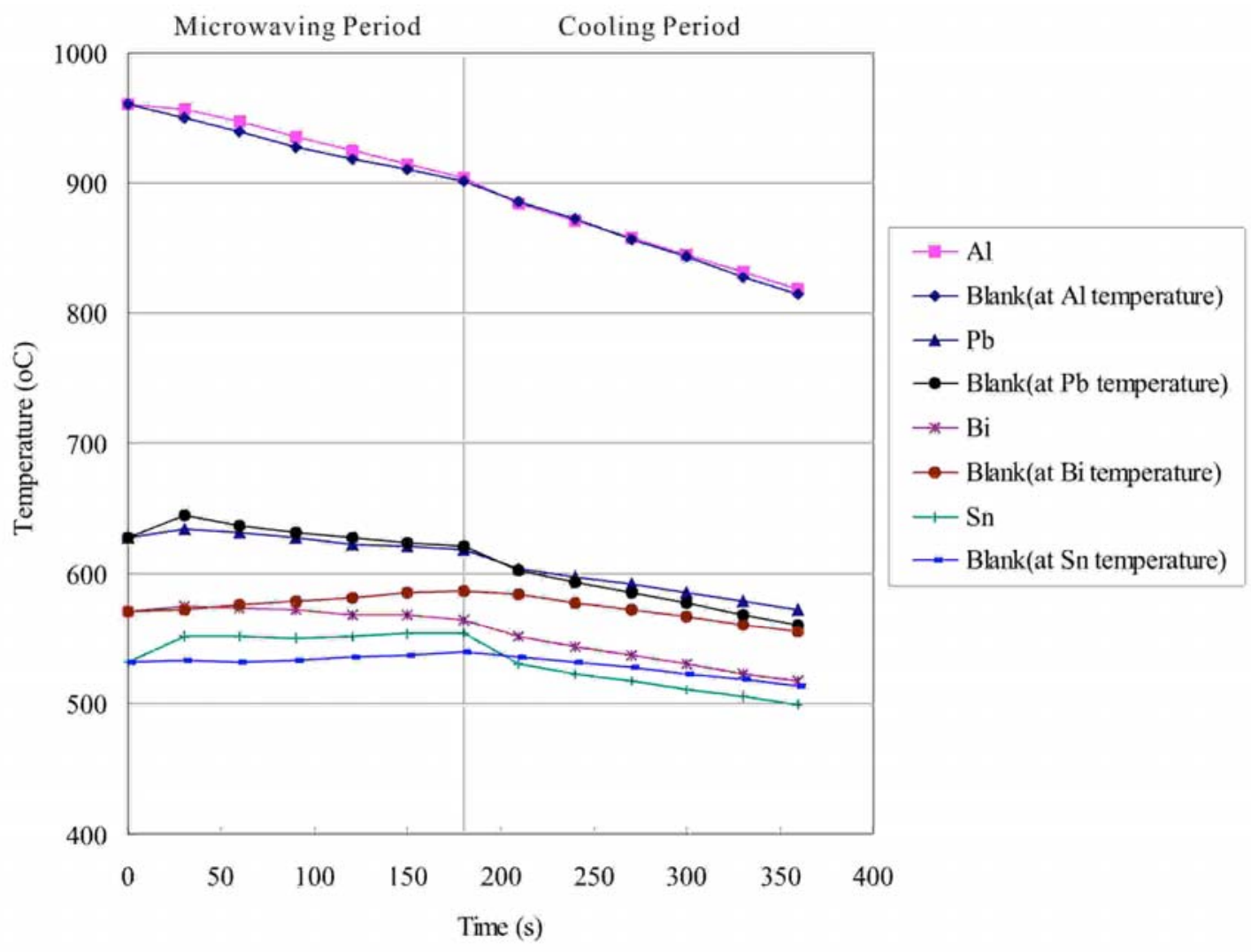

Figure 3. Temperature profile of different molten metals

There are two primary microwave heating mechanisms: dipolar and conduction. A third mechanism, interfacial, is often of limited importance. For dielectric materials such as water, introduction of microwave energy causes dipolar rotation, and then the frictional forces cause heat to be developed [4]. For electrical conductors, the mechanism 
is different; the electrons move under a microwave induced magnetic field, which then induces eddy currents, causing heat in a material due to its resistivity. These eddy currents create a secondary magnetic field opposite to the excitation field. A repulsive force can be caused which reflects the incident wave. This means most of the microwave energy does not penetrate into the material, but is reflected.

Skin depth $\delta_{s}$ is defined as the depth into the conductor from the surface at which the current density is $1 / e(0.368)$ of the value at the surface [5],

$$
\delta_{s}=\sqrt{\frac{2}{\omega \mu_{0} \sigma_{c}}}
$$

Where $\omega$ is the angular frequency and $\mu_{0}$ and $\sigma_{c}$ are the permittivity and conductivity of the conductor, respectively. For bulk metals, such as $\mathrm{Al}, \mathrm{Pb}, \mathrm{Bi}$, and Sn, the skin depths are very small, as seen in Table 1.

Table 1: Skin Depths of Bulk Metals

\begin{tabular}{|c|c|c|c|}
\hline Metals & $\begin{array}{c}\text { Resistivity at } 25^{\circ} \mathrm{C} \\
(\Omega m)\end{array}$ & Conductivity (S/m) & Skin depth (m) \\
\hline $\mathrm{Al}$ & $2.417 \mathrm{E}-08$ & $4.14 \mathrm{E}+07$ & $1.58079 \mathrm{E}-06$ \\
\hline $\mathrm{Pb}$ & $1.92 \mathrm{E}-07$ & $5.21 \mathrm{E}+06$ & $4.45541 \mathrm{E}-06$ \\
\hline $\mathrm{Bi}$ & $1.07 \mathrm{E}-06$ & $9.35 \mathrm{E}+05$ & $1.05179 \mathrm{E}-05$ \\
\hline $\mathrm{Sn}$ & $1.15 \mathrm{E}-07$ & $8.70 \mathrm{E}+06$ & $3.44815 \mathrm{E}-06$ \\
\hline
\end{tabular}

For molten metals, things are a little different. The resistivity coefficients [6], resistivities [6] and skin depths of molten metals are given in Table 2.

Table 2: Resistivities and Skin Depths of Molten Metals

\begin{tabular}{|c|c|c|c|c|c|c|}
\hline $\begin{array}{c}\text { Molten } \\
\text { metals }\end{array}$ & $\begin{array}{c}\text { Resistivity at } \\
25^{\circ} \mathrm{C}(\Omega m)\end{array}$ & $\begin{array}{c}\text { Temperatur } \\
\text { e coefficient } \\
\alpha\left(1 /{ }^{\circ} \mathrm{C}\right)\end{array}$ & $\begin{array}{c}\text { Goal } \\
\text { temperat } \\
\text { ures }\left({ }^{\circ} \mathrm{C}\right)\end{array}$ & $\begin{array}{c}\text { Resistivity } \\
\text { of molten } \\
\text { metals } \\
(\Omega m)\end{array}$ & $\begin{array}{c}\text { Electric } \\
\text { Conductiv } \\
\text { ity }(\mathrm{S} / \mathrm{m})\end{array}$ & Skin depth (m) \\
\hline $\mathrm{Al}$ & $2.417 \mathrm{E}-08$ & 0.004308 & 960 & $2.42 \mathrm{E}-07$ & $4.13 \mathrm{E}+06$ & $5.00201 \mathrm{E}-06$ \\
\hline $\mathrm{Pb}$ & $1.92 \mathrm{E}-07$ & 0.0042 & 628 & $9.50 \mathrm{E}-07$ & $1.05 \mathrm{E}+06$ & $9.91058 \mathrm{E}-06$ \\
\hline $\mathrm{Bi}$ & $1.07 \mathrm{E}-06$ & 0.0046 & 571 & $1.28 \mathrm{E}-06$ & $7.81 \mathrm{E}+05$ & $1.15038 \mathrm{E}-05$ \\
\hline $\mathrm{Sn}$ & $1.15 \mathrm{E}-07$ & 0.0046 & 532 & $4.80 \mathrm{E}-07$ & $2.08 \mathrm{E}+06$ & $7.04462 \mathrm{E}-06$ \\
\hline
\end{tabular}

Skin depths of molten metals are little higher than the values of the bulk metals. However, in comparison to the sample radius $(8 \mathrm{~mm})$, the skin depths are relatively neglectable. This means that most of the energy is reflected. Only a small amount of energy is constrained in the thin layer and the heat produced in the very thin skin is not 
enough to heat up the whole sample. This is evident in the experiment, when the temperature dropped or remained constant during microwave irradiation. It was also observed that different metals have different temperature fluctuation. In theory, the skin depth and thus the temperature increase should be in the sequence $\mathrm{Bi}>\mathrm{Pb}>\mathrm{Sn}>\mathrm{Al}$. However, the temperature data from the experiment showed $\mathrm{Sn}>\mathrm{Al}>\mathrm{Pb}>\mathrm{Bi}$. This phenomenon can not be explained at this point, and depends on future work.

\section{CONCLUSION}

From the temperature profile, molten metals are primarily microwave reflectors, as determined by their intrinsic properties and conduction mechanism. Microwave irradiation cannot be employed for heating purposes in processes dealing with molten metals. However, for application concerns where molten metals could be an end product, because the molten metals are not heated by microwave irradiation, microwave-molten metal interaction will not cause any processing problems such as thermal run away. Future work may focus on adding small amounts of nonreactive microwave absorbers into molten metals to increase their absorption ability.

\section{REFERENCES}

1. N. Standish and H. Worner: Iron \& Steelmaker, 1991, vol. 18(5), pp. 59-61.

2. David E. Clark and Willard H. Sutton: Annu. Rev. Mater. Sci., 1996, vol. 26, pp. 299331.

3. Willard H. Sutton: Am. Ceram. Soc. Bull, 1989, vol. 68, pp. 376-386.

4. Roger Meredith: Engineers' Handbook of Industrial Microwave Heating, $1^{\text {st }}$ ed., The Institution of Electrical Engineers, London, United Kingdom, 1998, pp. 19-33.

5. Paul R. Karmel, Gabriel D. Colef, Raymond L. Camisa: Introduction to Electromagnetic and Microwave Engineering, $1^{\text {st }}$ ed., John Wiley \& Sons Inc., New York, NY, 1997, pp. 246-247

6. David R. Lide: CRC Handbook of Chemistry and Physics, $79^{\text {th }}$ ed., Chemical Rubber Publishing Co., Boca Raton, FL, 1998 